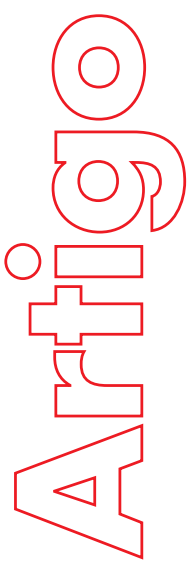

Revista

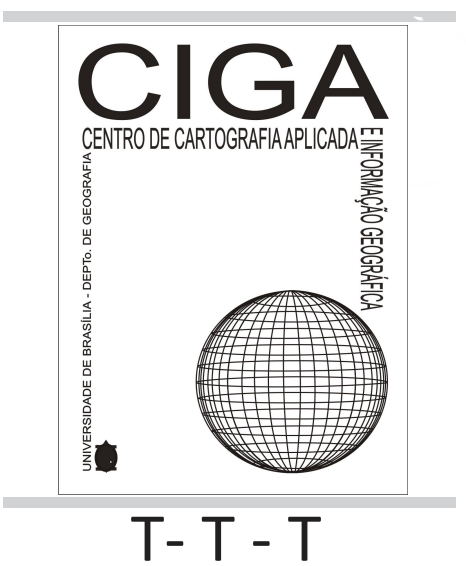

Revista Eletrônica: Tempo - Técnica - Território, V.11, N.2 (2020), 87:98 ISSN: 2177-4366

\section{ANÁLISE DA ABORDAGEM AFRO-BRASILEIRA NO LIVRO DIDATICO "GEOGRAFIA: O MUNDO EM TRANSIÇAO".}

\author{
Ana Beatriz Heinzelmann Machado
}

p. $87-98$

Como citar este artigo:

Machado, A. B. H.

ANÁLISE DA ABORDAGEM AFRO-BRASILEIRA NO LIVRO DIDÁTICO

"GEOGRAFIA: O MUNDO EM TRANSIÇÃO" - Revista Eletrônica:

Tempo - Técnica - Território, v.11, n.2

(2020),p.87:98 ISSN: 2177-4366.

Disponível em: http://periodicos.unb.br/index.php/ciga/

Este obra está licenciado com uma Licença

Creative Commons Atribuição - Não Comercial 4.0 Internacional. 


\title{
ANÁLISE DA ABORDAGEM AFROBRASILEIRA NO LIVRO DIDÁTICO “GEOGRAFIA: O MUNDO EM TRANSIÇÃO”.
}

\author{
Ana Beatriz Heinzelmann Machado \\ Graduanda em Geografia pela Universidade de Brasília, Disciplina GEOAFRO - $1^{\circ}$ Semestre 2020 \\ E-mail: anabheinz@gmail.com
}

\begin{abstract}
RESUMO: As questões geográficas afro-brasileiras demandam à atenção da sociedade perante a ressignificação de determinados estereótipos e discriminações. Os preconceitos são oriundos de uma estrutura racista dominante que assola os mais diversos âmbitos sociais e que persiste em tornar invisível um Brasil formado em grande parte pelas referências africanas. O racismo como uma ideologia em um sistema de dominantes estimula que as diferenças e as diversidades, as quais deveriam ser consideradas riquezas, sejam interpretadas pejorativamente, dando base a argumentos de dominação e estigmas de superioridade. Nesse contexto, o papel da educação, mais uma vez, fazse necessário. A partir da análise de um livro didático destinado ao Ensino Médio, foram observados alguns pormenores que dizem respeito à maneira que o grupo afrodescendente é abordado, às contextualizações que são realizadas e à permanência de estigmas e visões deturpadas, ou puramente incompletas, acerca das matrizes africanas no ambiente escolar, bem como os aspectos que, mediante tal fato, devem ser repensados.
\end{abstract}

Palavras-chave: Geografia Afro-brasileira, Educação, Livro didático, Representatividade, Estereotipagem

\begin{abstract}
The geografic afro-brazilian issues demand the attention of society about the reframing some stereotypes and discriminations. The prejudices are arising from a dominat racist structure witch ravages the most several social areas and witch persist in make an invisible Brazil formed, in most part, by the african references. The racism as an ideology in a dominant system encourages that the differences and diversity, witch should be considered as riches, be interpreted pejoratively, giving base to arguments of dominantion and superiority stigmas. In that context, the education contribution, again, it is necessary. From the analysis of a didatic book destineted to the High School, were observed some details that concerns to the way the african descendants grups are approached, to the contextualizations witch are made and to the permanency of stigmas and deturpated prospects, or just purely incompleted, about the african matrices at school environment, as well as the issues that, considering that fact, should be rethought.
\end{abstract}


Keywords: Afro-Brazilian Geography, Education, Courseware, Representativeness, Stereotyping

\section{INTRODUÇÃO}

O sistema escravista no Brasil foi abolido em 1888 e seus reflexos continuam vigentes. Não se pode falar em abolição integral quando se percebe o racismo estrutural fossilizado de maneira bruta na população. As referências afro-brasileiras são tratadas com invisibilidade e, por vezes, quando abordadas são motivos de preconceitos e discriminações. A contradição encontra-se no fato de que são as matrizes africanas uma das maiores diretrizes no que tange à formação do território brasileiro. Em torno disso gira, pois, um enorme paradoxo: nega-se uma das fontes que moldaram a própria cultura no Brasil, tornando-a invisível. A estrutura social que possibilitou a manutenção do racismo é constatada desde às leis que contribuíram para o movimento abolicionista. A própria Lei Áurea, a qual libertava os escravos, acabava por deixar os negros às margens da sociedade - gerando consequências que se manifestam em meios jurídicos, econômicos, ideológicos e educacionais. A política de estado, por sua vez, ampara majoritariamente o status de certa inexistência da comunidade afro-brasileira. Nesse contexto, é crucial considerar a educação uma das alternativas existentes que caminham em direção a reverter o cenário.

É obrigatório o ensino sobre História e Cultura Afro-Brasileira nos estabelecimentos de Ensino fundamental e Médio, oficiais e particulares, segundo a Lei n 10.639, de 9 de janeiro de 2003 (Brasil, 2003). Evidentemente, a obrigatoriedade tende a ser acompanhada no que diz respeito à abordagem dos materiais didáticos, que devem ter base em aspectos os quais a própria legislação atribui. Entretanto, mais importante do que tal fato é a democratização de um conteúdo que se encontre, deveras, completo e representativo.

O conteúdo programático a que se refere o caput deste artigo incluirá o estudo da História da África e dos Africanos, a luta dos negros no Brasil, a cultura negra brasileira e o negro na formação da sociedade nacional, resgatando a contribuição do povo negro nas áreas social, econômica e política pertinentes à História do Brasil. (BRASIL, 2003, grifo do autor)

Afora isso, a Base Nacional Comum Curricular (BNCC) estabelece parâmetros de habilidades e de competências a serem desenvolvidas e aprimoradas ao longo de cada ano escolar. Baseando-se no Ensino Médio, existem 3 (três) competências específicas voltadas ao entendimento das culturas étnicas que compõem a sociedade brasileira. A saber: a Competência Específica 2, que preza pela análise da formação territorial seguida pelo entendimento das relações de poder e o papel geopolítico 
dos Estado-nações, tem como uma de suas habilidades comparar e avaliar os processos de ocupação espacial a considerar os conflitos, as características socioeconômicas, políticas e a diversidade étnicocultural; a Competência Específica 5, de maneira geral, tem foco na identificação e combate das injustiças, violências e preconceitos, capacitando o estudante a desnaturalizar condutas e costumes em ações de preconceito, discriminação e desigualdade; por fim, a Competência Específica 6, visando produzir a participação em debates críticos, apresenta como uma das habilidades a identificação e a análise das demandas e dos protagonismos dos povos indígenas e do grupo com descendência africana, de modo a viabilizar ações para a redução de desigualdades étnico-raciais (BRASIL, 2018). Ainda assim, há a urgente necessidade da visibilidade ao princípio de compreensão do espaço social como um meio que abriga comunidades étnico-raciais distintas, com culturas, histórias e experiências que os caracterizam e que são igualmente valiosas para a constituição do território brasileiro. Apesar de toda determinação, à nível da constituição educacional, os materiais didáticos e a literatura infantil utilizada nas escolas, por vezes, não estão de acordo com as determinações. A estrutura e os assuntos ainda tendem a tratar a temática com superficialidade, com referências incompletas ou distorcidas, bem como com juízo de valor de teor eurocêntrico.

Logo, observa-se que, formalmente, existe amparo no que se refere a difusão da temática afrobrasileira. Entretanto, com discernimento e uma análise crítica, tem-se que considerar de que forma tais conteúdos estão sendo transmitidos, isto é, sabe-se da obrigatoriedade imposta, mas há de ser averiguado se a abordagem realmente preenche lacunas e promove a representatividade dos grupos étnicos ou se manifesta apenas o mero cumprimento de uma regra.

Por fim, o objetivo primordial do presente estudo é realizar uma análise do livro didático de Ensino Médio “Geografia: o mundo em transição” para a resolução dos questionamentos pertinentes à visibilidade da população afrodescendente no Brasil e de que maneira estes são representados ao público de estudantes por meio dos materiais escolares.

\section{FICHA TÉCNICA DO LIVRO “GEOGRAFIA: O MUNDO EM TRANSIÇÃO”}

José William Vesentini, autor de "Geografia: o mundo em transição”, é formado em Bacharelado em Geografia pela Universidade de São Paulo - USP (1973) e em Licenciatura em Geografia (1974) na mesma universidade. Possui doutorado em Geografia Humana (1985) também pela USP, onde é professor e pesquisador do Departamento de Geografia da FFLCH. Define em seu próprio Currículo Lattes sua área de atuação com “ênfase em Geografia Política/geopolítica e ensino da geografia, atuando em específico nos seguintes temas: nova ordem mundial, política e território, 
geopolítica brasileira, questão ambiental, ensino da geografia no século XXI”. (CURRÍCULO DO SISTEMA CURRÍCULO LATTES, 2010)

O livro didático tem o público-alvo de estudantes de Ensino Médio e visa contribuir com o preparo dos alunos para obtenção de ótimo desempenho em exames tais quais Enem, demais vestibulares e avaliações seriadas. Ademais, Vesentini (2010) igualmente preza pelo objetivo da proposta a formação de um cidadão ativo no contexto globalizado, possibilitando independência nos processos da conscientização crítica, isto é, para que esteja apto a questionar, entender, aprender e, principalmente, aprimorar o raciocínio crítico do entendimento acerca do espaço em que se encontra imerso. Assim, foi publicada a 1ª (primeira) edição por meio da Editora Ática no ano de 2010.

A estrutura se divide em três partes, as quais manifestam unidades com seus respectivos capítulos. Por ser um conteúdo destinado ao Ensino Médio em formato de volume único, prima por assuntos geográficos de maneira geral e tem por início “Geografia Geral - Conceitos Principais”, continua ulteriormente com unidades de “Geografia Geral e do Brasil - Problemas e Alternativas” e, por fim, “Geografia do Brasil - Humana, física e regional” respectivamente. A saber:

\section{PARTE 1 - GEOGRAFIA GERAL}

UNIDADE 1 - Geo-história e geocartografia (com 6 capítulos)

UNIDADE 2 - Geoeconomia (com 6 capítulos)

UNIDADE 3 - Geopolítica (com 5 capítulos)

UNIDADE 4 - Geofísica (com 6 capítulos)

\section{PARTE 2 - GEOGRAFIA GERAL E DO BRASIL - PROBLEMAS E ALTERNATIVAS}

UNIDADE 5 - Geodemografia (com 6 capítulos)

UNIDADE 6 - Globalização e regionalização (com 5 capítulos)

UNIDADE 7 - As potências asiáticas (com 5 capítulos)

UNIDADE 8 - Periferias e perspectivas mundiais (com 5 capítulos)

\section{PARTE 3 - GEOGRAFIA DO BRASIL - HUMANA, FÍSICA E REGIONAL}

UNIDADE 9 - Brasil: formação territorial e geoeconomia (com 5 capítulos)

UNIDADE 10 - Aspectos da população brasileira (com 4 capítulos)

UNIDADE 11 - Geofísica do Brasil (com 6 capítulos)

UNIDADE 12 - Geografia regional do Brasil (com 5 capítulos) 
Na página destinada exclusivamente à apresentação do material, Vesentini (2010) explicita tratar-se de uma abordagem crítica e construtivista. Ele discorre os impactos da revolução técnicocientífica e as rápidas e inesperadas mudanças que desde 1980 vêm transformando o mundo. Posteriormente, explica os novos sentidos da educação com a finalidade de propiciar aos alunos habilidades e competências para o estímulo da indução, quebra de preconceitos e reconstruções.

\section{CONCEITUAÇÕES E ABORDAGEM ÉTNICO-RACIAL}

\section{O ESPAÇO GEOGRÁFICO}

Os capítulos iniciais são utilizados para trazer à luz conceitos geográficos importantes. Fazse uma conceituação bastante breve da Geografia, exibida apenas como o estudo do espaço geográfico, dando margem ao enfoque, também sucinta, da história da Geografia enquanto esfera do saber. O tópico é encerrado após uma explicação sobre Alexandre Von Humboldt e Karl Ritter. Nada aborda acerca de Friedrich Raztel e Vidal de la Blache, por exemplo, nem sobre as importantes contribuições para a Geografia Regional. Além disso, limita-se em retratar uma versão resumida do contexto mais clássico da área, de forma a ignorar outras perspectivas e correntes desenvolvidas e/ou aprimoradas no decorrer da evolução do pensamento geográfico. Não explora outros conceitos básicos os quais podem facilitar o entendimento do contexto ao aluno, como paisagem e território. Assim, a única conceituação tratada é a de espaço geográfico: “[...] o local ou o meio onde vivem os seres humanos: a superfície terrestre.” (VESENTINI, 2010, p.12).

\footnotetext{
O campo de preocupações da geografia é o espaço da sociedade humana, em que homens e mulheres vivem e, ao mesmo tempo, produzem modificações que o (re)constroem permanentemente. [...] o espaço geográfico não é apenas o local de morada da sociedade humana, mas principalmente uma realidade que é a cada momento (re)construída pela atividade do ser humano. (VESENTINI, 2010, p.12 e p.13)
}

Portanto, o estudante, ao fazer uso do material, não recebe uma base consolidada da história e evolução do pensar geográfico em decorrência da ausência de maiores entendimentos acerca da linha do tempo dos estudos relacionados ao ramo, impossibilitando a produção de uma contextualização sobre a própria disciplina.

\section{A GEOGRAFIA AFRO-BRASILEIRA}

A PARTE 3 - GEOGRAFIA DO BRASIL aborda na Unidade X o capítulo 52 intitulado “População brasileira (III): etnias”. Esse capítulo traz os tópicos: 
1. “Grupos étnicos formadores do Brasil”, no qual Vesentini (2010) descreve as constituições indígena, negro africana e branco europeia do território brasileiro. Retrata a intensa miscigenação que ocorreu e deu origem aos mestiços e "pardos” (aspas utilizadas pelo próprio autor). Apresenta, ainda, a questão da precariedade dos recenseamentos gerais no que diz respeito às etnias, exemplificando a problemática da declaração parda que se caracteriza como uma iniciativa individual de fuga ao preconceito - uma prática que já vem diminuindo a cada recenseamento, sendo, inclusive, uma importante consideração a receber ênfase.

Segundo Anjos (2020, p.47):

Historicamente, vários setores da população brasileira têm sido vítimas de discriminação e preconceitos de toda a ordem. Entre os tipos de discriminação, a étnica, que atinge particularmente o contingente de ascendência africana no país, é sem dúvida a de maior extensão social e territorial.

É evidente o reflexo do racismo estrutural no que diz respeito a produção dos censos demográficos no Brasil. Para Anjos (2020), ser descendente das referências africanas, além de ser um esforço excepcional na busca da visibilidade perante um sistema dominante, é, inclusive, um fator de risco e, principalmente, uma adversidade para a própria manutenção da sobrevivência. Tal fato explica, claramente, o motivo pelo qual alguns indivíduos de ascendência africana optam por se autodeclararem "pardos".

Uma tabela, na página 621 do livro em análise, divide os brasileiros em etnias - brancos, negros, pardos, amarelos, indígenas e não declarados - conforme dados dos censos demográficos de 1950, 1980 e 2000 pelo Instituto Brasileiro de Geografia e Estatística (IBGE). O número de brancos, que inicialmente em 1950 caracterizavam 61,7 \% da população, diminuiu relativamente nos anos censos seguintes de 1980 e de 2000, compondo respectivamente 54,7\% e 53,7\% do total de brasileiros. Com o grupo dos negros a situação é diferente: no início, com 11\%, diminuiu para 5,9\%, porém aumentou para 6,2\% em 2000. Os pardos, por sua vez, crescem de 26,5\% para 38,5\% e depois decaem em $0,1 \%$ no último recenseamento apresentado, enquanto o número de não declarados aumenta em todos registros, indo de $0,2 \%$ para $0,3 \%$ até alcançar 0,9\%. Para os amarelos o valor se mantém constante nos dois primeiros apontamentos (0,6\%) e no cenário ulterior entra em queda de 0,2\%. O número de indígenas, por fim, só apresenta o último registro de 0,4\%, isto porque em 1950 e 1980 a etnia amarela englobava indígenas e asiáticos, já em 2000 somente os asiáticos.

Posteriormente, o material disponibiliza-se a uma explicação acerca da dúvida de credibilidade dos dados por não levarem em conta a origem real dos indivíduos, e sim a cor da pele por meio da auto declaração, além de criticar a noção de “pardo” e de “amarelo” pela imprecisão que não abrange uma única etnia. Igualmente aborda que alguns descendentes de indígenas e negros se 
declaram "brancos”, porém é uma atitude cada vez menos incidente em virtude de vantagens conquistadas pelos indígenas (demarcação de terras) e pelos afrodescendentes (cotas).

A análise realizada por Vesentini (2010) é também discutida por Anjos (2020) ao declarar que a problemática do recenseamento se revela na intenção de descobrir o número real da população de ancestralidade africana.

\begin{abstract}
Primeiro, a questão demográfica do "Brasil africano" que continua sem uma resposta e representação adequada, isto porque os critérios de aferição oficiais do povo levam à subestimação do número real de cidadãos de matriz afro-brasileira que integram o país. O Instituto Brasileiro de Geografia e Estatística (IBGE) continua agrupando os indivíduos em brancos, pretos, amarelos e pardos, considerando brancos, pretos ou amarelos os que assim se declararem e os "outros" ficam classificados como pardos. (ANJOS, 2020, p.49)
\end{abstract}

Tal perspectiva merece, deveras, o devido destaque. Vesentini (2010) afirma que os dados estatísticos referentes aos censos dificilmente refletem a realidade porquanto exageram no número de brancos e diminuem o de afro-brasileiros.

2. “Grupo negro ou afro-brasileiro”. O autor contextualiza o decorrer da história dos africanos e a categoria "negro" imposta pelo colonizador no processo escravista. Depois disso, relata sobre a situação atual da população afrodescendente no Brasil, com alguns índices de desigualdade evidente. Vale ressaltar, curiosamente, uma pequena afirmativa que, ainda com tantas evidências, soa como detectável flexibilidade quanto à notória situação desigual que atinge o país: “[...] tudo parece indicar que, em geral, ele [afro-brasileiro] continua a ocupar um lugar inferior na hierarquia social [...]” (VESENTINI, 2010, p.629, grifo nosso).

O presente subtópico discorre sobre os primeiros africanos trazidos para o território em 1532 e sobre a introdução e a abolição da escravatura e o entendimento com base na economia internacional e interesses europeus, principalmente. Ademais, faz referência à lucratividade do tráfico de escravos, mas não segue além. Explica o processo da abolição em escala global e nacional, a iniciativa do Reino Unido em extinguir o comércio de escravos e a ascendência da Revolução Industrial à época.

Portanto, apresenta-se de maneira extremamente superficial e sem pormenores esclarecidos. Tem apego em fatos históricos sem quaisquer análises reais dos aspetos sociais que hoje retratam as consequências de todos os quatro séculos do sistema escravista - sequer faz alusão ou associação de um fato ao outro.

Vesentini (2010), em geral, limita-se a expor a abolição da escravatura em 13 de maio de 1888, e o Brasil sendo o último país a tomar tal atitude. Ulteriormente, já se direciona para o subtópico “Situação do atual do negro”. Não explica de que modo ocorreu a marginalização dos 
afrodescendentes na sociedade nem comenta sobre os paradigmas que ainda hoje os tornam invisíveis e excluídos no que diz respeito à oportunidade e à própria cultura. Tem início da seguinte maneira:

\begin{abstract}
Desde o final da escravatura até os dias de hoje, a situação do afro-brasileiro alterou-se bastante. Mas teria ele passado a desfrutar as mesmas condições econômicas e sociais que os brancos? Tudo parece indicar que, em geral, ele continua a ocupar um lugar inferior na hierarquia social, ganhando em média salários mais baixos e vivendo em piores condições que a população branca. (VESENTINI, 2010, p. 629)
\end{abstract}

A interpretação desenvolve brevemente em cima de dados estatísticos, os quais comprovam a desigualdade social que assola os afro-brasileiros. O livro aborda a diferença na média dos rendimentos mensais dos “pardos”, correspondente a apenas $80 \%$ em comparação ao da população branca. Já o dos negros representa 74\%, também quando comparado aos brancos; indica o percentual de pobreza dos grupos de descendência africana e as taxas de desemprego; declara piorada a situação dos negros, perante as demais etnias, levando em consideração os preconceitos e o estereótipo de inferioridade. Sobre este, afirma que alguns requisitos de empregos solicitam a exigência de boa aparência como justificativa eufemística exclusiva para não contratar negros. Sem nenhuma contextualização, o autor segue apenas mostrando estatísticas para comprovar sua ideia. Não explica o porquê da situação evidenciada nem o que aconteceu no decorrer dos séculos para atingir tal realidade.

Por fim, ainda neste capítulo, são expostas, unicamente, três imagens, que exprimem a finalidade de representar esse grupo. São elas:

I. A primeira imagem é a Litografia Negros no fundo do porão do navio (1835) de Johann Moritz Rugendas. Nela estão representados dezenas de afrodescendentes - homens, mulheres e crianças - semi ou completamente nus no porão de um navio. Apresentam-se de variadas formas: dormindo, amamentando bebês, apenas sentados com aspecto pensativo, machucados e/ou visivelmente tristes e abatidos. Ademais, alguns olham fixamente para três indivíduos brancos e bem vestidos, um deles com uma lamparina, que parecem ter acessado o local a fim de retirar o corpo sem vida, o qual já está sendo carregado, de um dos negros

II. A segunda imagem mostra uma afro-brasileira na função de empregada doméstica (Fonte: Silvestre Machado/Opção Brasil Imagens). Ela está na varanda de um apartamento realizando o serviço de passar as roupas. Abaixo do retrato o seguinte comentário: “[...] No Brasil, mais de $80 \%$ das empregadas domésticas são de ascendência afro-brasileira. E os negros, assim como as mulheres, são vítimas de preconceitos daqueles que os consideram “inferiores” e acham que devem ocupar posições subalternas no conjunto da população.” (VESENTINI., 2010, p.629) 
III. Por fim, a terceira é uma montagem com três fotografias de personagens negros de grande importância no contexto brasileiro. Da esquerda para a direita: Gilberto Gil (Fonte: Katia Lombard/Folha Imagem), Joaquim Barbosa (Fonte: Ana Araújo/Editora Brasil) e Milton Santos (Fonte: Ronald Guimarães/Editora Brasil). A legenda discorre:

\begin{abstract}
Apesar de tantas mazelas que envolvem a condição do negro no Brasil, alguns indivíduos rompem as restrições do preconceito. Exemplos, da esquerda para a direita: Gilberto Gil (1942-), cantor, compositor e ex-ministro da Cultura; Joaquim Barbosa (1954-), ministro do Supremo Tribunal Federal; Milton Santos (1926-2001), geógrafo. (VESENTINI, 2010, P.630)
\end{abstract}

A última caracteriza-se, portanto, como uma imagem de representatividade. As outras duas, no que as dizem respeito, apenas se limitam a reforçar o estereótipo do afro-brasileiro: escravidão e empregos inferiores, de maneira geral. Nada têm a declarar acerca da representatividade das matrizes africanas - quilombos, terreiros, culinária, capoeira, dentre outros - bases da formação estrutural e cultural brasileira. Ou seja, reforça a ideia estereotipada do grupo e, além disso, não faz jus às demais referências que existem sobre o mesmo.

A história única cria estereótipos, e o problema com os estereótipos não é que sejam mentira, mas que são incompletos. Eles fazem com que uma história se torne a única história (ADICHIE, 2009, p.15)

3. “Os grupos étnicos brancos e os asiáticos”, por fim. Esse último relata resumidamente a história dos imigrantes europeus - portugueses, espanhóis, italianos, alemães, eslavos, holandeses - e de origem asiática - japoneses e sírio-libaneses.

\title{
CONSIDERAÇÕES FINAIS
}

O livro didático em questão, de fato, não reproduz a ideia de considerar as matrizes africanas como uma verdadeira e real referência para a formação estrutural do Brasil. Ele, sim, realiza o enfoque afro-brasileira enquanto uma composição da população, porém transparece a uma concepção puramente de ancestralidade, ou seja, o equivalente a dizer que a única e exclusiva procedência referencial africana atualmente existente no território se limitaria à cor da pele. Isso pode ter base no fato de que o material não expõe absolutamente nada diferente de: a) a história do período escravocrata; b) a situação do afro-brasileiro nos dias atuais; ambas de maneira extremamente breve e sem grandes explicações. Nada discorre sobre a cultura africana, a qual inegavelmente compõe uma das bases estruturais do Brasil - capoeira, terreiros e quilombos, por exemplo. Ademais, destaca-se uma controvérsia quanto à referência do próprio autor em considerar a abordagem crítica e construtivista, em que, entretanto, pouco disponibiliza conteúdo eficiente da temática em questão para 
que o estudante esteja realmente apto a desenvolver uma análise de cunho crítico ou, simplesmente, ser introduzido a perspectivas diferentes daquelas culturalmente estereotipadas. Bem como não apresenta quaisquer posicionamentos acerca do mesmo tema, apenas faz o uso de matemáticas e estatísticas a fim de comprovar o que a realidade esboça, sequer contextualizado os fatos com o passado. Ou seja, nota-se uma defasagem de criticidade em relação ao que de fato é proposto inicialmente.

A falta de representatividade coloca-se hoje sendo uma das maiores responsáveis para o contexto de invisibilidade da referência africana no Brasil. Necessário esclarecer que o entendimento de ausência representativa não deve ser confundido, de maneira alguma, com inexistência. A matriz existe, mas persiste invisível pela falta de reconhecimento, em primeiro lugar, do próprio Estado. Por exemplo, à nível educacional - em que obviamente não cabe generalizações - constantemente a questão afro-brasileira é tratada da mesma forma tal qual o presente material: superficial e incompletamente.

A visão de tendência eurocêntrica representada à nível didático contribui para a falta de aprofundamento no que diz respeito às matrizes, o que bastante contribui para a absorção da ideia de falsa inexistência e a relativização da profundidade e da enorme influência dessa cultura na sociedade. Portanto, no que tange ao âmbito educacional, a representatividade é fundamental. É de extrema importância que, desde tenra idade, o indivíduo esteja imerso em um ambiente que o proporcione a percepção das diretrizes afro-brasileiras, com claras representações, em especial, nos materiais didáticos. Uma vez que o livro em análise é do Ensino Médio, seria primordial o ajuste no sentido a dar prioridade a análises amplas e apresentações, como exemplos, da capoeira, do entendimento concreto acerca das populações quilombolas e da desmistificação dos terreiros de umbanda e candomblé. A educação é um dos maiores meios de se permitir abrir espaço a tais temáticas e tornase falha quando se limita em trazer à luz representações completamente estereotipadas. Ao credibilizar uma versão histórica de quaisquer que sejam os fatos, comete-se o desvio de desvalorizar as demais, que são igualmente existentes. Segundo Adichie (2019), as histórias podem ter o uso baseado em funções de caluniar, porém, ao contrário, igualmente podem ser utilizadas para empoderamento e, por vezes, humanização. Não há dúvidas de tamanha a importância que se traduz uma versão histórica. Entretanto, essencial é entender que inúmeras são as histórias existentes e que tais visões podem despedaçar a dignidade de outro povo, mas podem repará-las também. Por isso a necessidade de permitir aos estudantes, independente da série escolar, uma concepção completa de todas as etnias existentes na formação territorial e cultural brasileira e, principalmente, de suas referências e proveniências. 
É impossível falar sobre a história única sem falar sobre poder. Existe uma palavra em igbo na qual sempre penso quando considero as estruturas de poder no mundo: nkali. É um substantivo que, em tradução livre, quer dizer "ser maior do que outro”. Assim como o mundo econômico e político, as histórias também são definidas pelo princípio de nkali: como elas são contadas, quem as conta, quando são contadas e quantas são contadas depende muito de poder. O poder é a habilidade não apenas de contar a história de outra pessoa, mas de fazer que ela seja sua história definitiva. (ADICHIE, 2019, p.14)

Outrossim, é mister que o material destine uma parte maior e considerável para tratar do assunto de grupos étnicos no Brasil e que valorize cada um em suas respectivas especificidades. O espaço destinado a tal abordagem é bastante inferior quando comparado a outras temáticas, entretanto não é de menor importância. Afora o fato de que é tratado com imensa superficialidade e bastante incompleto.

Por fim, faz-se necessária uma revisão da contextualização afro-brasileira destinada aos estudantes. Os profissionais da educação, ao disporem de pouco conteúdo disponibilizado pelo Estado sobre o tema, devem se empenhar em transmitir ensinamentos voltados, justamente, para a quebra dos preconceitos e a introdução das matrizes que ainda caracterizam-se invisíveis no meio social. A visibilidade aliada à representatividade é crucial, e a educação deve se portar em grande primazia quanto ao fornecimento de novas visões de mundo e desconstrução de estereótipos.

\section{BIBLIOGRAFIA}

ADICHIE, Chimamanda Ngozi. O perigo de uma história única. $1^{\mathrm{a}}$ Edição. Companhia das Letras, 2019.

ANJOS, R.S.A. Territórios Invisíveis do Brasil Africano: Cartografias e Tensões Sócio-Espaciais nos Terreiros Religiosos. In: REGO, N. \& KOZEL, S. (Orgs.) Narrativas, Geografias \& Cartografias - Volume 1. Eds. COMPASSO e UFRGS Geociências: Porto Alegre, 2020.

BRASIL. Lei $n^{\circ}$ 10.639, de 9 de janeiro de 2003. Altera a Lei $n^{0}$ 9.394, de 20 de dezembro de 1996, que estabelece as diretrizes e bases da educação nacional, para incluir no currículo oficial da Rede de Ensino a obrigatoriedade da temática "História e Cultura Afro-Brasileira", e dá outras providências. Disponível em: <https://legis.senado.leg.br/norma/552515>. Acesso em dezembro de 2020.

BRASIL. Ministério da Educação. Base Nacional Comum Curricular. Brasília, 2018.

CHIMAMANDA ADICHIE: o perigo de uma única história. Disponível em: $<$ https://www.ted.com/talks/chimamanda_ngozi_adichie_the_danger_of_a_single_story?language=ptbr>. Acesso em agosto de 2020 
VESENTINI. José William. Geografia: o mundo em transição. $1^{\mathrm{a}}$ edição. Volume Único. São Paulo: Editora Ática, 2010.

VESENTINI. José Wiliam. Currículo do sistema de Currículo Lattes. Disponível em: < http://lattes.cnpq.br/3945292708273502 >. Acesso em dezembro de 2020.

WEBNAR GEOAFRO 1 - O Brasil africano e a geopolítica do racismo estrutural do Estado. Disponível em: <https://www.youtube.com/watch?v=MwnI99_sFWs\&feature=youtu.be>. Acesso em agosto de 2020.

WEBNAR GEOAFRO 3 - O BRASIL AFRICANO E A EDUCAÇÃO BÁSICA HOSTILIZADA E RACISTA. Disponível em <https://www.youtube.com/watch?v=eX8WC55uRu0>. Acesso em setembro de 2020 . 